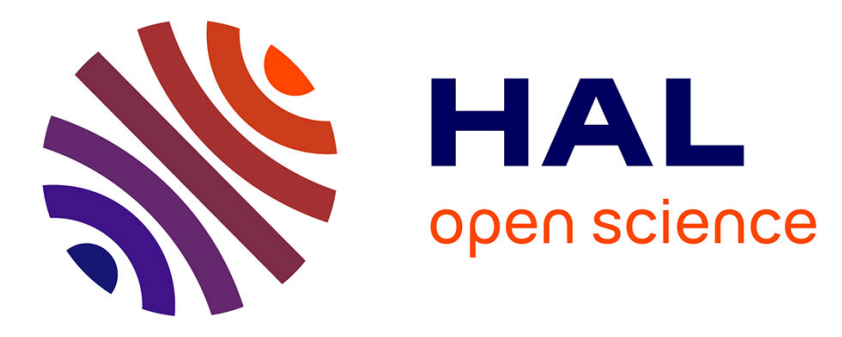

\title{
Media and the Internet Access Providers in an Era of Convergence
}

\author{
Pierre-Jean Benghozi, Françoise Benhamou
}

\section{To cite this version:}

Pierre-Jean Benghozi, Françoise Benhamou. Media and the Internet Access Providers in an Era of Convergence. The Values of Public Service Media in the Internet Society, Springer International Publishing, pp.193-213, 2021, Palgrave Global Media Policy and Business, 10.1007/978-3-030-56466-

7 11. halshs-03503861

\section{HAL Id: halshs-03503861 https://shs.hal.science/halshs-03503861}

Submitted on 8 Jan 2022

HAL is a multi-disciplinary open access archive for the deposit and dissemination of scientific research documents, whether they are published or not. The documents may come from teaching and research institutions in France or abroad, or from public or private research centers.
L'archive ouverte pluridisciplinaire HAL, est destinée au dépôt et à la diffusion de documents scientifiques de niveau recherche, publiés ou non, émanant des établissements d'enseignement et de recherche français ou étrangers, des laboratoires publics ou privés. 


\title{
Media and the Internet Access Providers in an era of convergence
}

\author{
Pierre-Jean Benghozi and Françoise Benhamou
}

Abstract

Technological breakthroughs are an enabler in the convergence between telecommunications operators and media. Close economic examination put at stake the interpretation based on vertical integration and complementary strategies of telecom operators and content producers.

Approach to convergence must be renewed because situation is not the same as 20 years ago. The multiplication of TV channels, the development of Internet and the growing bandwidths have resulted in the explosion of on line content. This contributed to the expansion and predominance of digital platforms that invested significantly in content production and network infrastructure. These original converging strategies call for regulatory issues because the changes raise new challenges associated with the new market structure: segmentation of regulation perspective, competitive and non-price strategies, net neutrality.

Keywords: Telecoms industry, Convergence, Media regulation, Telecoms regulation, Internet platforms

Françoise Benhamou is Professor of Economics at Sorbonne Paris Nord Univ. She was a member of the ARCEP (French independent agency in charge of the regulation of telecoms) from 2012 to 2018.

Pierre-Jean Benghozi is a CNRS research director and professor at the Ecole Polytechnique (Paris) and the University of Geneva. He was a member of the ARCEP (French independent agency in charge of the regulation of telecoms) from 2013 to 2019. 


\section{Introduction}

The media, and especially TV channels, have been transformed by a multifold movement triggered and supported by digitization. First, the scattering of content and audiovisual programs started with the proliferation of channels at the very beginning of the 80 s, and was emphasized with new forms of production, distribution and online access. Distribution of content becomes more and more dependent on Internet providers, giving birth to logics of concentration around dominant technical players. Second, delinearization developed, in the framework of a platform economy (centered on new entrants).

Thus, the emergence of information and communication technologies has challenged the existing rules of the game. In particular, the historical boundaries are blurred between media and telecom industries, with different means: diversifications, mergers, acquisitions, cooperations. Telecom companies got closer to TV companies in order to enrich their offers and TVs are looking for ways to develop their distribution by getting closer to telecoms and Internet players. Consequently, both industries have an interest in convergence, but project different strategies and visions behind the same term.

In the course of about twenty years, technological developments have thus precipitated the media into a vast set of communication media where sounds, images and information of all kinds are mixed. From a public policy point of view, the consequences arise at both ends of the chain, on the side of the providers of the service and on the side of the public that receives it. In the past, media regulation had to face technological changes on many occasions but has been able to adapt itself, benefiting from a double trigger ruling, national and european, which makes it easier to address some of the limits brought about. However, faced with a system that has reached its limits, the public player have to face today brand new pitfalls since the new wave of transformation brought about by digital technology calls into question the very objectives and tools of media regulation. Telecom and internet regulation focuses on infrastructures, competition and on the protection of personal data. It is less interested in other aspects (ethic, cultural diversity, genre, etc.), which have historically formed the basis of the regulation of the audiovisual and media : they are difficult to implement on services that mix a logic of traditional linear TV and a logic of content aggregation platform.

Therefore regulation, whether for telecoms or $\mathrm{AV}$, must rethinks its traditional modes of intervention and changes its paradigm: how to consider the definition of relevant markets, how to take into account the neutrality of networks, applications and terminals, and, in a nutshell, how to migrate towards a regulation of platforms. In order to better understand such a change in industrial strategies and regulation, this chapter raises two main questions: while convergence has existed for a long time, how firms revise their strategies in a new environment characterized by the market power of giant platforms? To what extent does this circumstance call for a reinvention of regulation? In After recalling the challenges of convergence in Part 2, we exposes the economic models of both industries (Part 3), then we clarify the rationality of convergence (Part 4). Part 5 stresses the importance of platforms and the way they disrupt the conditions of typical convergence. Part 6 raises the question of regulation and Part 6 concludes.

\section{Main challenges of convergence}

Technological breakthroughs have been an enabler and a major factor in the convergence telecom operators and media (Xing, Ye, \& Kui, 2011). It can be considered the result of the parallel evolution of the telecom networks, the increase in throughput and capacity of and the emergence of new 
generations of terminals. Actually, these changes have accompanied and supported the development of technological upheavals in content distribution (Waterman, Sherman, \& Wook Ji, 2013).

Berec (2016) emphasizes that the process of "technological convergence" is at the origin of an economic de-compartmentalization in Telecom industries but also in energy and transportation. These infrastructure networks were previously organized in silos and now face changing market boundaries. New strategies are emerging through a number of firms of network industries. They seek to exploit the same intangible resources (knowledge, information, etc.) or physical practicalities (infrastructure, technology, etc.) at different levels of the value chain. It potentially modifies the boundaries between these three industries and creates new synergies

For many years, the debates on the convergence between networks and content have been the subject of numerous observations and appraisals in the academic literature (cf. Benghozi and Jackel, 1999).

In the same way, on the industrial side, the assumption has been the support of many movements. The takeover of media groups by telecom operators has rekindled the questions already raised in the early 2000s about the prospects for success of a "content-pipe convergence" strategy. Telecom operators have been active in the purchase of sports rights and film and series rights for the creation of TV channels or OTT services, and even in the purchase or creation of audiovisual and/or film production companies. Moreover, it was also the justification for many strategies of mergers and acquisitions between telecom, cable TV and media companies (see Table 1 for the French case in 2018).

Table 1. Top deals in Technologies, media and telecoms, France, 2018

\begin{tabular}{|l|l|l|c|}
\hline Target & Buyer & Sector & $\begin{array}{l}\text { Value } \\
(\mathbf{\epsilon M})\end{array}$ \\
\hline GEMALTO NV & THALES GROUP & Technology & 5424 \\
\hline HAVAS SA & VIVENDI SA & Media & 3733 \\
\hline EIRCOM GROUP LIMITED (64.5\% STAKE) & ILIAD SA; NJ HOLDING & Telecom & 2994 \\
\hline SAGEM SÉCURITE & $\begin{array}{l}\text { ADVENT INT. CORP. BPI } \\
\text { France SA }\end{array}$ & Technology & 2425 \\
\hline ARICENT INC. & ALTRAN TECHN. & Technology & 1700 \\
\hline BAMBORA GROUP AB & INCENICO & Technology & 1500 \\
\hline ASCO POWER TECHNOLOGIES, L.P. & SCHNEIDER ELECTRIC & Technology & 1068 \\
\hline FPS TOWERS & ATC EUROPE & Telecom & 727 \\
\hline SFR GROUP (4.13\% STAKE) & ALTICE & Telecom & 633 \\
\hline DOMINION WEB SOLUTIONS, LLC & EURAZEO, GOLDMAN & Technology & 625 \\
\hline $\begin{array}{l}\text { BOUYGUES TELECOM SA (1,800 TELECOM } \\
\text { TOWERS) }\end{array}$ & SACHS & & \\
\hline GRUPO MEDIA CAPITAL, SGPS, S.A. & ALTEX TELECOM & Telecom & 500 \\
\hline LES CINEMAS GAUMONT PATHE SAS & PATHE & Media & 440 \\
\hline AUSY SA & RANDSTAD France & Media & 380 \\
\hline SES-IMAGOTAG & BOE TECHN. GROUP & Technology & 367 \\
\hline SQS SOFTWARE QUALITY SYSTEMS AG & ASSYSTEMS TECHN. & Technology & 356 \\
\hline EXA CORPORATION & DASSAULT SYSTEMES & Technology & 337 \\
\hline NEXTRAQ, INC & MICHELIN & Technology & 285 \\
\hline TEADS INC. & ALTICE & Media & 285 \\
\hline AB GROUPE SA & MEDIA ONE SPAC & Media & 237 \\
\hline SOII
\end{tabular}

Source : Pwc, 2018.

Regulators themselves have taken up the challenge by developing the concept of net neutrality ( $\mathrm{Wu}$, 2003), in order to prevent the negative consequences of such industrial reorganizations. 
Convergence between telecoms and media hang on a twofold challenge. Firstly, both media and telecom industries strive for increasing the number of consumers and subscribers thanks to network effects ${ }^{\text {ii }}$. Secondly, they need to build and reinforce customers' loyalty, as well as to cope with wider competition. Contents appear as a tool for telecom operators in order to capture and care for a large number of subscribers so as to enhance, in addition to their financial power, their marketing knowhow and real customer-oriented values. Therefore, there is a mutual interest of both industries for strategies of vertical integration and diversification in order to attract and lock in customers by supplying a diversity of contents and creating high switching costs for customers to stay in a closed ecosystem.

However, on close examination, one may wonder about this simple interpretation of convergence based on crossed and complementary strategies of telecom operators and content producers. Convergence seems paradoxical. On the one part, the rise of online digital platforms is shaking up a value chain that has simply sent operators and content producers back to the drawing board until recently. On the other part, the hypothesis of symmetrical convergence strategies has to be discussed: telecoms and media providers do not share the same goals, and their expectations are not necessarily reciprocal. Moreover, their economic models are quite different - and even opposed. For example in France, telecoms do not want to pay for audiovisual content, while media companies argue that contents attract subscribers and increase their willingness to pay for Internet access. Consequently, regulators consider concentration may threat the independency of content suppliers and the neutrality of the Internet, which remains at the core of digital policies in Europe.

\section{Two economic models with different economic grounds}

The main economic feature of convergence is that it is supported by network industries. Their architecture benefited from recent progress in the decoupling of the transport and service layers of the network (Santos et al., 2008). This means that, whenever a provider wishes to activate a new service, he can do so by defining it directly on the service layer regardless of the transport layer, thus making the services independent of transport details. Consequently, the efficiency of vertical integration is one of the reasons frequently put forward in order to explain convergence.

Beyond this generic observation, however, it is important to detail the more specific characteristics of the industries involved in convergence. Media and telecommunications are, on the one hand, fixed cost economies. On the other hand, they produce goods and services that generate externalities and network effects.

In both industries, fixed costs are very high while variable costs are very low. But there are deep differences in their economic models. The importance of fixed costs is much higher for telecoms, which can be qualified infrastructure economics, while they are much lower in the case of media, which are mostly economics of prototypes. Convergence players present both profiles. On the one hand, players for whom content distribution is an ancillary activity intend to increase the audience or traffic of a site, to increase the consumption of commercial sites, or to sell equipment. On the other hand, players for who content distribution is the core activity and whose concerns are similar to those of traditional media players : their business model is based on the ability to aggregate and editorialize content: their revenues are proportional to the success of content whose risks are balanced.

In the case of telecoms, rapid entry and exit are difficult, since firms face irrecoverable investments supported for their telecommunication infrastructure: their rate of investment in relation to sales in 
Europe varies between 15\% (UK) and 23\% (France)! Operators are also facing a very significant increase in these investments in order to address the growing requirements for the renewal of their fixed and mobile networks (cf. Table 2). Those investments require a pretty long period of time in order to be amortized, compared with other industries (see chart 1). On the one hand, they are made necessary by the rapid development of network technologies and protocols. On the other hand, they must respond the growing needs of consumers (annually doubling, with, on average, the volume of data they consumed) and the necessity to differentiate from competitors by the quality and territorial coverage of their network.

Table 2. Investments of telecom operators, France, 2014-2018, €Billion

\begin{tabular}{|l|l|l|l|l|l|}
\hline Years & 2014 & 2015 & 2016 & 2017 & 2018 \\
\hline $\begin{array}{l}\text { Mobile } \\
\text { infrastructure }\end{array}$ & 2.4 & 2.3 & 2.7 & 3.0 & 2.8 \\
\hline $\begin{array}{l}\text { Fixed } \\
\text { infrastructure }\end{array}$ & 4.7 & 5.5 & 6.2 & 6.6 & 7.0 \\
\hline Total & 7.1 & 7.8 & 8.9 & 9.6 & 9.8 \\
\hline
\end{tabular}

Source. Fédération Française des Télécoms.

Chart 1. Duration of return on capital invested by sector, France, average 2013-2017, $\mathrm{N}^{\circ}$ years

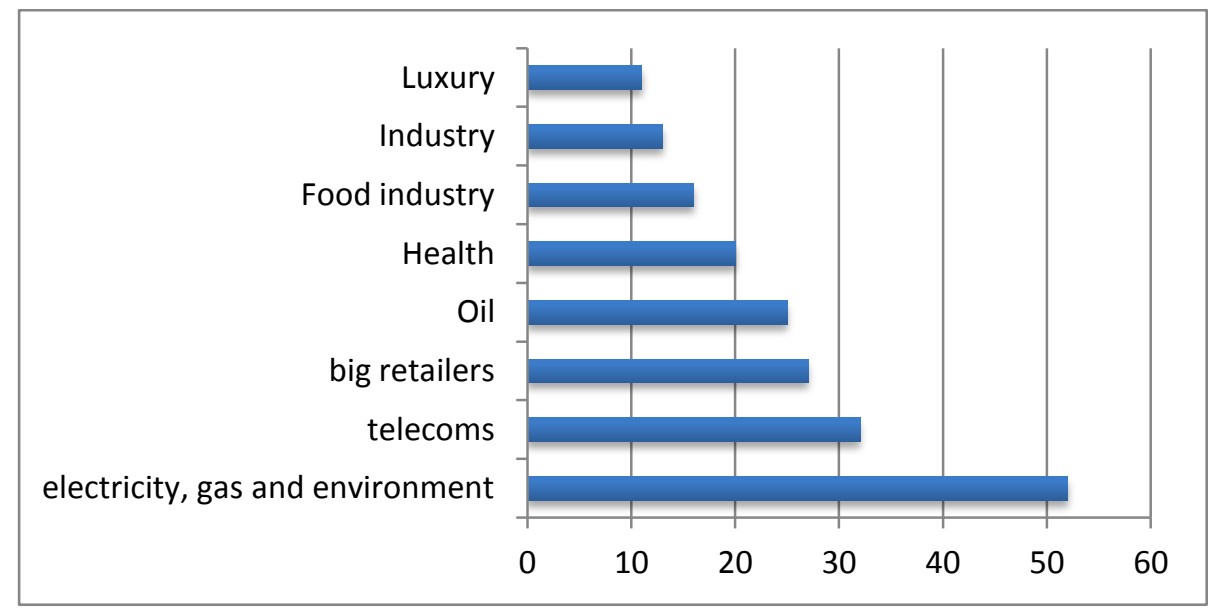

Source Fédération Française des Télécoms.

Therefore, from the marketing viewpoint, firms seek a rise in the number of subscribers in order to lower the level of competition, by reducing prices, and wish to increase the average revenue per user (ARPU). Both actions are less contradictory than they appear. The strategy of firms in order to overcome this tension relies on locking consumers into their ecosystems through high switching costs.

In a fixed-cost economy, controlling and retaining a consumer base is an important advantage for stabilizing and securing revenues over the long term. It represents also an opportunity for a development based on an increase in ARPU. Therefore, operators seek for the monetization of new services.

Conversely, media rely on two-sided businesses (Rochet and Tirole, 2003) in which the value of ads depends of the ability of contents to attract a large number of consumers, and where, conversely, the monetization depends on the quality and attractiveness of the content - and especially the exclusive 
contents - provided to consumers. Content producers and distributors want to create portfolios of rights on a wide range of qualities in order to capture enlarged audiences. They need an access to powerful distribution networks to ensure the best possible distribution of their contents, to reach new audiences and to imagine new ways of making the most of them. In this way, television channels have expanded the audiovisual offer available on fixed broadband and very high-speed broadband networks by developing catch-up video solutions on their websites. The distribution of this non-linear content is based on the Internet access service, which offers any user the possibility to access the Internet at any time.

The growth of these investments goes beyond the audiovisual sector alone and more broadly concerns all rights holders, such as sport, for example (see Table 3).

Table 3. Premier League Football TV rights value, €Billions

\begin{tabular}{|l|l|l|l|l|l|}
\hline Period & $1992-1997$ & $2001-2004$ & $2007-2010$ & $2013-2016$ & $2016-2019$ \\
\hline Value & 0.3 & 1.6 & 2.3 & 4 & 6.9 \\
\hline
\end{tabular}

Source: AFP.

\section{The rationality of convergence}

Vertical integration is rooted in neoclassical approaches that view the firm as an alternative to the market. It assumes that vertical integration allows internalization of costs and would result in economies of scale.

Such integration was natural and designed from the outset by the cable operators. Cable operators are in fact infrastructure players who have built their network for the sole purpose of delivering cable television. It is only recently that these cable operators have broadened their offer by also providing Internet access via their network.

Convergence is therefore a strategy inherited and revisited from early digital infrastructures. The logic of convergence is in the genes of cable operators who have always built a pipe / supply relationship for TV content. The situation has, however, changed considerably since.

For TV channels (as it was for Cable operators in the beginning), content distribution must be a profitable business, especially in the context of the overbidding in the ownership of premium rights. On the contrary, for telecom operators, the content strategy is not an end in itself, but essentially supports the development of their broadband subscriptions, both fixed and mobile. As a matter of fact, the TV business and investment in contents and rights acquisition are not necessarily directly profitable for them: the important thing being that it enables them to win new subscribers or retain existing customers.

\subsection{A basic form of complementarity between actors}

At first glance, convergence is justified on a basic form of complementarity between actors. Indeed, infrastructure operators need applications, services and content to justify and provoke the use (and 
remuneration) of their networks. In such a framework, the recurring challenges of Telecom / AV convergence is part of a classical vertical integration perspective supported by a simplified vision of strategies of firms based on cost optimization and on the idea that controlling contents makes it possible to capture and develop consumer loyalty.

One hypothesis could be that convergence would allow actors to compensate for the weaknesses of their respective business models: attracting telecom subscribers by supplying a wide range of contents on the one side (at one bottom of the value chain) and ensuring the quality of content distribution (at the opposite bottom of the value chain) (see figure 1). Therefore the base of connected consumers is enlarging, whose willingness to pay is high because they benefit from a high quality of service and diversity in content supply.

Figure 1. Telecom operators in the content production value chain

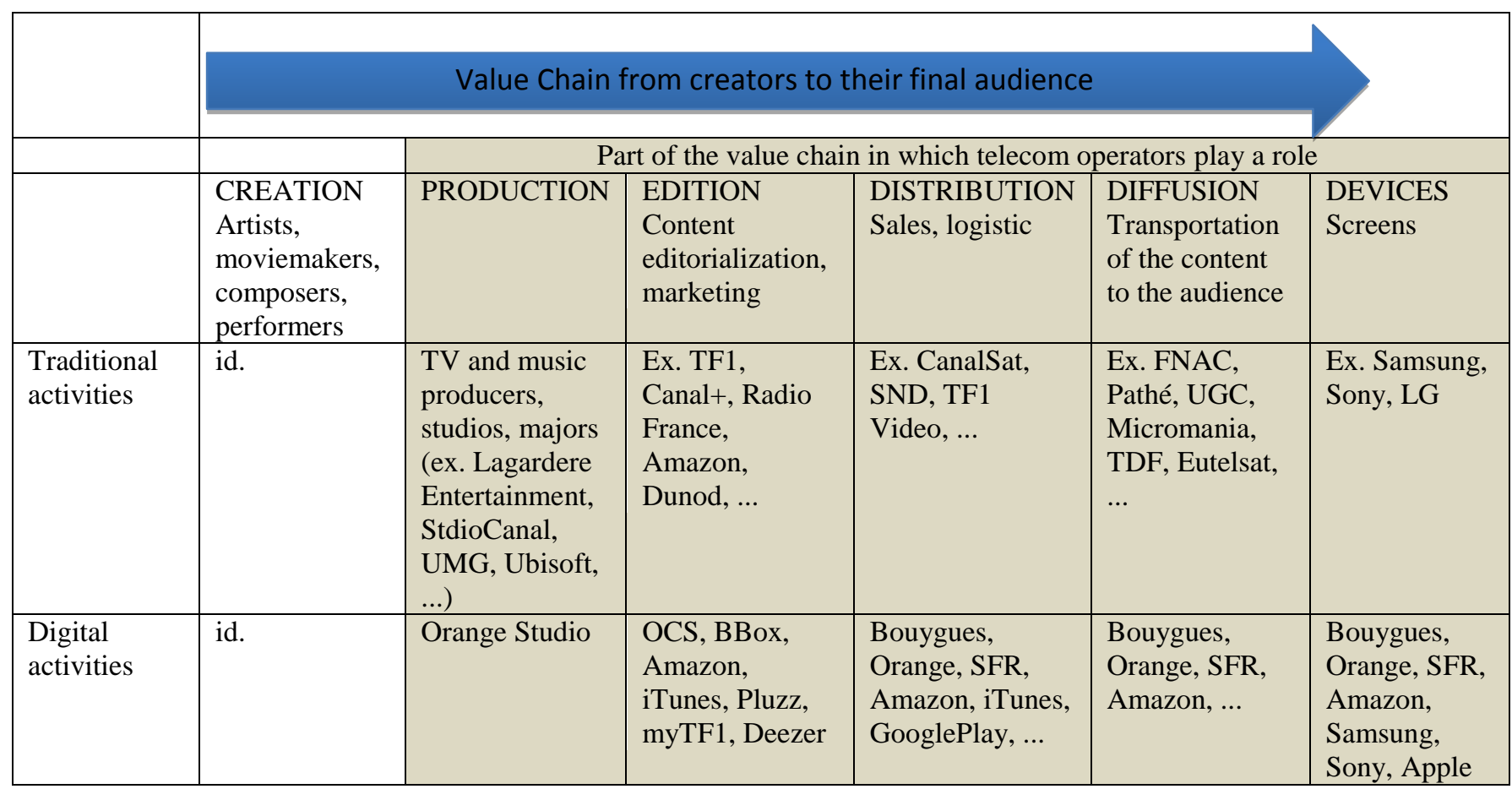

Source FFT \& Roland Berger, 2013.

One of the lever and consequence of the attractiveness of content is their wide availability and therefore a massive increase in data traffic over the networks. It means corresponding investment to upgrade networks (FttH, FttB, 4 and 5G) and equipment (Content Delivery Networks) contributing to enhance the viewer experience as well.

Convergence is the response to major changes in technology driven behavior. Powerful and very affordable to buy and use, smartphones and touch tablets are driving this convergence. They are all the strongest because of the mobile nature of these tools. In a way, they confer the gift of ubiquity through digital technology to their users. Such evolution rebounds the hyper-fragmentation of audiences due to the abundance of channels, sites, networks and media brands, coupled with the delinearization of content consumption. 


\subsection{Convergence and triple-play offers}

With the spread of multi-service offerings, audiovisual content has become an element of the strategy of Internet service providers. They support the new form of competition in the retail Internet access markets. Therefore, audiovisual distribution markets necessarily affect the fixed (and mobile) Internet access business models. Moreover, the prospect of accessing higher quality audiovisual content is a factor in migration to very high speed Internet access.

In France, Internet Service Providers (ISPs) used the capacity of fixed broadband and very high-speed networks very early on to offer innovative audiovisual offerings. Curien and Moreau (2007) highlight that for network operators, content distribution appears to be an engine for growth. This was compulsory, given the decline in voice revenues driven by competition and the rise of VoIP.

Some 15 years ago, this led to the first mobile application platforms developed first in Japan and then in Europe, and this was the basis for major convergent takeover strategies (AOL Time Warner, Vivendi). At the same time, operators were also responding in the fixed-line networks, They launched the marketing of triple play multiservice offers that included Internet access, voice telephony over broadband and access to an audiovisual package that generally included linear television offers of around one hundred channels, including those broadcast on DTT, followed by innovative non-linear services such as catch-up television.

The operator Free was the first to offer a unique subscription comprising the three services in France, in December 2003. The commercial success of triple-play offers, combined with the major technical developments experienced by fixed networks, has resulted in a significant proportion of households accessing television via their Internet connection. In 2016, 49\% of households with at least one television set were equipped to receive television via ADSL or optic fiber cable and for $29 \%$ of households, wireline networks (including cable) are the only ways to receive television (source: CSA) $)^{\text {iii. }}$. While the main operators have aggregated, within their multiple play offer, Internet access supply and distribution of edited bundles or services, not all of them have moved up the value chain by adding content production to their business portfolio.

In a very competitive retail market for Internet access, revenues from additional services such as content represent only a minor share: $12 \%$ in 2015, according to Arcep. But they contribute to the attractiveness of offers, which gives players with rights to certain content a significant bargaining power and the ability to bring network externalities into play by favoring certain ISPs to the detriment of others.

\subsection{The variety of strategies relying on convergence}

The French, Italian, Israeli, etc. telecom markets have developed fierce price competition. But price wars have limits and companies began to develop distinct strategies of price discrimination in order to avoid the clipping of margins and the commoditization of supply. These strategies were substitutes or complements, depending on the case. In France, the biggest telecom company, Orange, focused on the quality of the network. Free, the more recent entrant company, put forward cuts in prices, without any direct investment in contents ${ }^{\text {iv }}$. But simultaneously, Free aimed to be positioned on the layer just above via its box: the use and ergonomics of the consumption of contents. 
The two other French operators SFR and BYT have early chosen the integration of content and other services. Whatever the strategy, in all cases, content and services competition appeared progressively as a substitute for price competition. For example, Kiosque Premium launched by SFR offers an unlimited subscription to 450 newspapers and magazines at a price of $€ 9,99$ a month.

In a nutshell, one can say that the current convergence does not start from content publishers anxious to access a large market via new distribution channels and to find financial support (as in the Messier era - the chairman of Vivendi in 2000-2002), but from telecom companies trying to put an end to price wars and to prioritize product differentiation. Those competitive strategies are part of monopolistic competition where competition necessarily involves discrimination by the quality of goods and not, as in the case of a natural monopoly, by prices.

Such non-price strategy of product differentiation can be supported through three main levers: the size of catalogues, their variety, and their curation. Actually, distribution and production are not the only key to develop attractiveness of contents. In the context of hyper-offering provided through the internet, aggregation of contents is a crucial issue since all contents are not alike (Benghozi and Benhamou 2010). Premium content are a key element and operators can target some overpaid specific contents (namely sports or exclusive series) while aggregating as well long tail low paid contents.

The importance of aggregation, cataloguing and therefore control of distribution has historically been the basis of the cable operators' bouquet and bundle strategies. In the current phase of maturity of the Internet, the appetite for convergence or integration movements has therefore increased for similar reasons. According to Bakos and Brynjolfsson (1998), the bundling strategy of selling a set of separate information assets for a single price often produces higher profits and greater efficiency than selling the same assets separately.

\subsection{The limits of strategies based on convergence}

One can wonder the degree of sustainability of convergence strategies. For network operators, sustainability is questioned by the ability to make major investments in infrastructures simultaneously with new investments to uphold the purchase and/or production of programs. Investing in content would distract resources from infrastructure development, at a cost for social and economic collective welfare. For content players, the situation is just as difficult. They are generally weakly capitalized structures, ensuring production investments in "project" mode, and must ensure very heavy investment plans in terms of both Capex (Capital expenditure) and Opex (Operational expenditure). Pogorel and Preta (2014) note that as more actors embrace ambitious one stop shop strategy, with direct to consumer video services at the core, the jury is still out to value which "converged" services provider contributes in the best possible way to strengthening their audience and bottom line.

In France like in almost all European countries, telecoms face a significant trade off or struggle between revenues and volume. On the one hand, they observe a regular decline in ARPU regarding the connectivity services they provide, in contrast to the increase in revenues from content aggregator platforms and customers' expenses on SVOD services. On the other hand, they have to address a growing volume of connections and data, mainly resulting from audiovisual non-linear services like Netflix. 
Convergence strategies are considered as a solution to meet several objectives in tension: long-term value creation by securing the consumers with a relatively high willingness to pay for premium content, fueling margins by increasing ARPU, increasing the number of basic subscribers, being proactive by anticipating new business models based on data and advertising, and so on.

The risk for telecoms is that content costs are growing faster than revenue line. As a matter of fact, owning content is not necessarily a must-have to secure premium content provision to customers. Similarly, customers' loyalty, data aggregation and revenue streams can also be secured by alternative services (banking, smart home services...).

\section{Internet platforms and disruption}

Online media consumption has risen sharply on all different devices (fixed PCs or smartphones on the move) to the detriment of linear consumption of broadcast or digital TV. Therefore, convergence becomes part of a three-way game that not only concerns content providers and telecoms, but the major Internet platforms as well. They have created new forms of intermediation different from technical infrastructures, but also from content publishers: OTTs provide services, hosting, etc. in the production and editorialization of content.

For telecoms, the evolution towards content seems difficult because they do not have a culture or an organization of their activity corresponding to that of the cultural world (short-term investments in risky projects, more creative training than engineers...). In this context, convergence does not only meet an objective of vertical integration or the economic targets described above. It also becomes a response of telecoms to the market power of OTT. By creating a privileged relation with media, they try to internalize the distribution of contents and to re-capture the market power that platforms appropriate for themselves.

On the other hand, OTTs don't have the skills and the ways of thinking of media producers, but their considerable resources enable them to develop or/and purchase rapidly very rich programs with some worldwide successes (think of House of Cards) but also more uneven results. For example, in 2020, Amazon's SVOD offering has 150 million customers, formally almost as many as Netflix (167 million). However, the two are hardly comparable despite their growth in both cases and the attractiveness of the titles in their catalogues. The Amazon Prime Video catalogue is on the one hand much smaller than that of Netflix. Secondly, the majority of Prime customers subscribe primarily to take advantage of the benefits of free e-commerce delivery.

In any case, platforms disrupt the value chain by creating new playing field and preventing direct access to content for telecoms. Moreover, Google or Facebook don't hesitate to invest in infrastructure (fiber, network, etc.), creating an additional source of competition for telecom operators.

In addition, telecom networks sometimes show limit regarding the consequences of convergence. As a matter of fact, the growth of video distribution initiates network congestion on peak time or failures in case of large events. These economic and technological difficulties strengthen the integration movements undertaken by the OTTs towards infrastructure networks. Indeed, the main digital platforms are incented to control IP interconnection investing in networks (backbones, urban fiber networks...) and building their own $\mathrm{CDN}$ in telecom data centers. 
The arrival of players from the Internet is thus introducing new competition for telecom operators; strategies combine mergers and acquisitions (see AT\&T and Time Warner or Comcast and Sky), and deals and alliances, (as in the cases of Deutsche Telecom and Netflix, Sky and Open Fiber, or Vodafone and Liberty Global).

Until now, their market has been essentially national in scope and coverage, but it is becoming increasingly international, driven by players, most often North American, who have the capacity to address a very largely international audience and therefore to acquire rights on an almost global scale.

\section{To what extent does convergence meet the major regulatory challenges}

If firm strategies are somewhat convergent, it is not really the case for regulatory practices. The new configurations that are being put in place cover, in practice, different legal frameworks, actors and fields of regulation. As a result, regulatory actions and decisions are themselves broken down into several segments.

Digital platforms obviously challenge the scope of regulation by imposing combined regulation dealing with personal data, market power and net-neutrality. This raises, in particular, the following question: is ex ante regulation, prior to the implementation of the competition rules, appropriate? Should such intervention come from a sectorial regulator, who defines a priori the playground of the various economic actors? Or can it be carried out through the instruments available to the Competition Authority, which punishes abusive behavior a posteriori?

\subsection{Why should convergence be regulated?}

Converging environment changes the traditional regulatory dynamics. OECD (2016) emphasizes that in a constantly changing world of communications, policy makers and regulators are confronted with familiar challenges as well as new ones. The familiar challenges include the promotion of competition, investment, innovation, and consumer choice while meeting a number of social objectives such as universal service, emergency services, privacy and security. However, new regulatory challenges emerge when technological developments turn of great magnitude and often disruptive and when services and applications are decoupled from networks. As Cortez (2014) points out, regulators are challenged by disruptive innovations and regulation can become stale and counterproductive. In a context of technological and economic disruption, regulators have to cope with different goals.

Regulators are focusing on two specific competitive risks in particular. The first risk corresponds to a possible vertical partitioning of the market. This can result from the vertical integration of players or the widespread of exclusivity legal provision. A second risk is the possibility of anti-competitive foreclosure strategies and market pre-emption in favor of dominant operators (Marty 2011).

To address these issues, the scope of regulation encompasses a series of levers. First, the definition of relevant markets, in order to assess the market power of companies, is quite important. What divisions of the telecoms and media markets are appropriate? Should we consider separately the mobile and fixed access to Internet? Should we consider media as a whole? Second, the consumer's benefits and losses should be identified, i.e. restrictive access to contents, lock in, prices, etc. Third, the indirect effect of mergers on the quality of Internet access infrastructures should be taken into account, and fourth, net neutrality, which is still in force in Europe, is questioned by convergence strategies. 
One can wonder whether considerations linked to the peculiarities of content industries should be taken into consideration before framing and accepting the converging operations, partnerships or M\&A in particular. In that respect, the questioning of traditional boundaries between industries entails risks for competition. For instance, Internet service providers pose a significant threat to traditional operators in the audiovisual market. Not only do triple play offers allow direct competition with TV channels, but also their technology offers telecommunication firms and consumers many advantages in term of non-linear uses of TV (replay, catch-up TV and video on demand).

Moreover, in the field of telecoms, investments are national priorities in order for the whole population to be connected to Internet services. This point may be considered as a market failure leading to the need for regulation rules. For example, the promotion of cultural diversity can be considered as a goal of cultural policies, that can be better served by concentration than competition, or conversely.

\subsection{The tools of regulation}

Competition regulators, telecoms regulators and TV regulators have to pay attention to the effects of convergence. Indeed, to what extent is it possible to accept converging bundles : are they compatible with new forms of competition? To address this question, public actors have a toolbox enabling them to tackle regulation from several angles. We can illustrate this from two complementary standpoints: the competitive approach and the preservation of net neutrality.

As for other M\&A, in view of convergence competition, regulators first watch the share in market power and evaluate the risk of abuse of dominant position, which is reflected, among other elements, in the issue of prices.

When content providers and internet service providers offer complementary goods or services, in the absence of integration, neither party internalizes the profit loss inflicted on the other party by raising its price: in consequence, vertical integration may reduce prices. Also, vertical integration may reduce the underinvestment that arises with independent parties, as the investment generates benefits for the firm producing the complementary product. In practice, the magnitude of these gains is unclear, but the empirical literature from other industries identifies many examples of efficiency gains from vertical integration (Lafontaine and Slade 2007).

In a two sided market perspective, Belleflamme and Peitz (2020) review recent work that aims at better understanding the possible pro- or anti-competitive effects of convergence. They stress two specific non-price strategies: exclusivity as the contractual obligation to singlehome and price transparency as the disclosure of information about otherwise unobserved prices paid by users. Their results may sound paradoxical for regulators. They find that a monopoly platform is willing to remedy this problem by being transparent about all prices, whereas competing platforms would prefer more opaqueness in general.

Beside the competitive price dimensions, there is a broad consensus on the objectives of providing the widest possible access to online services and of encouraging access, innovation and diversity of content and services. Anticompetitive concerns arise because an Internet service provider may offer its own services and charge termination fees for competing content providers, potentially leading to partial or full exclusion. Content providers are able to differentiate from competitors satisfying heterogeneous user tastes (Economides and Hermalin 2015). Then, vertical integration may lead telecom operators to favor their own contents and it is precisely to combat this risk that neutrality is 
aimed at. But a strict application by regulators may lead them to wrongfully exclude telecoms from activities linked to contents, in such a way that leading OTT platforms may finally take the economic power on cultural goods and services, as well as on networks infrastructure.

Nevertheless, regulators assume that an Internet service provider should be required to treat all data from all content providers in the same way, and they generally argue that net neutrality is essential because without it, Internet service providers could seek to control access to certain content according to their economic and strategic agreements. Net neutrality also prevents the possibility of providers charging end users an extra fee to access specific services. Yet, there is more discussion on implementation, i.e. on the contours and limits of net neutrality and on its possible negative externalities. No consensus fully emerged in the literature regarding its characterization (for example, Sidak 2006; Lee and Wu 2009).

As an illustration, Berec (2016) defines zero-rating as a situation "when an Internet Service Provider applies a price of zero to the data traffic associated with a particular application or class of applications."”. But for Somogly (2016), zero-rating harms consumers if content is unattractive, whereas it improves social welfare in the case of attractive content. Consequently, it is not automatically compatible with the principle of net neutrality, and calls for regulatory scrutiny.

\section{Concluding remarks}

Ultimately, the evolution of telecom networks, the generalization of nomadic screens and changing consumer habits have created a framework that is favorable to advanced forms of integration or partnerships between content players and network players:

- Telecom industrials need content to differentiate themselves and to increase ARPU,

- Telecom operators currently have investment capacities compatible with content financing and own the networks through which the bulk of content consumption is expected to take place in the coming years

- Content industries need to find new growth drivers and outlets at a time when consumption is changing and traditional revenues are under pressure.

The issue of convergence is not radically new: it was a hot topic at the very beginning of the digital wave. Yet, the context of convergence differs deeply from the 20 years ago. Firstly, the consumers have changed profoundly. They are connected and mobile, they want to get access to all content, any time, anywhere, on any device. Secondly, digital technology is profoundly changing the economic landscape, with more competition, new players on the Internet, and the need to be able to provide the best possible service to consumers.

As a consequence, the content economy relies on over-abundance rather than scarcity. For both media and telecoms, the threat of "uberization" is strong. Each media must ensure that it is differentiated thanks to its catalogue, creativity and production capacity. For its part, each network seeks, through non-price strategies, to avoid being reduced to a commodity, to a simple pipe.

Regulation should be revised correspondingly: the market power of platforms redefines convergence. The traditional regulation of convergence (through competition authorities) must move in order to integrate the regulation of platforms, which grab and capture contents. Regulation raises new stakes: access, cultural diversity, revenue sharing, and intellectual property rights. 
The future of convergence oscillates between two scenarios. On the one hand, we can consider that the two models of media and telecoms are so different that, despite the multiplication and recurrence of convergence attempts, they will fail ... as they did 20 years ago. But we can also assume, on the other hand, that there is an irretrievable movement, given the present multiplicity of mergers and alliances in a three players game instead of two.

Further analysis should include a wider scope of convergence that does not concern only media and content players. The major operators are developing digital services for their industrial customers: smart cities, energy, on-board telematics, healthcare, etc. In view of the recent movements observed among telecom operators, convergence also affects the world of finance, the world of smart homes, of online services, of cars and industrial applications.

\section{References}

Bakos, Y., \& Brynjolfsson, E. (1999). Bundling Information Goods: Pricing, Profits and Efficiency, Management Science, vol. 45(12), 1613-1630.

Belleflamme, P., \& Peitz, M. (2020). The competitive impacts of exclusivity and price transparency in markets with digital platforms, Concurrences (1), 2-7.

Benghozi, P. J., \& Jäckel A. (1999) What Convergence for which Media?, First European Audiovisual Seminar Proceedings, University of Turin, 5-8 dec.1998, University of West of England Press.

Benghozi P.J., \& Benhamou, F. (2010). The Long Tail: Myth or Reality?, International Journal of Arts Management, 12(3), 43-53.

BEREC, (2016). BEREC guidelines on the Implementation by National Regulators of European Net Neutrality Rules, http://berec.europa.eu/eng/document_register/subject_matter/berec/download/0/6160-berecguidelines-on-the-implementation-b_0.pdf

Cortez, N., (2014). Regulating disruptive innovation, Berkeley Technology Law Journal (29), 175-228.

Curien, N., \& Moreau, F. (2007). The Convergence between Contents and Access: Internalizing the Market Complementarity, Review of Network Economics, 6(2), 1-14.

https://www.academia.edu/4264779/The_Convergence_between_Contents_and_Access_Internalizing the Market Complementarity

Economides, N., \& Hermalin, B.E. (2012). The Economics of Network Neutrality, Rand Journal of Economics, 3(4), 602-629.

Fédération Française des Télécoms (2019). Les chiffres-clés 2019 du secteur des télécoms et des grands enjeux à venir, https://www.fftelecoms.org/etudes-et-publications/etude-economique-2019telecoms-premiers-acteurs-numerique/

Lafontaine, F., \& Slade, M. (2007). Vertical Integration and Firm Boundaries: The Evidence, Journal of Economic Literature, 45(3): 629-685. 
Lee, Robin S., \& Wu, T. (2009). Subsidizing Creativity through Network Design: Zero-Pricing and Net Neutrality, Journal of Economics Perspectives, 23(3): 61-76.

Marty, F. (2011). Convergence numérique et risques de forclusion des marchés : Quel partage des rôles entre politiques de concurrence et régulation sectorielle ? Concurrences, 3, 28-34.

OCDE (2016). Digital Convergence and Beyond: Innovation, Investment, and Competition in Communication Policy and Regulation for the 21st Century, http://www.oecd.org/officialdocuments/publicdisplaydocumentpdf/?cote=DSTI/ICCP/CISP(2015)2/FI $\underline{\text { NAL\&docLanguage }=E n}$

Pogorel, G., \& Preta, A. (2020). Media and Telecom in an Age of Convergence Europe in a Transatlantic and International Perspective, Working Papers Telecom Paris Tech.

Santos, J., Gomes, D., Sargento, S., Aguiar, R. L., Baker, N., Zafar, M., \& Ikram, A. (2008). Multicast/broadcast network convergence in next generation mobile networks, Computer Networks, 52(1), 228-247. https://doi.org/10.1016/j.comnet.2007.09.002

Sidak, G.J. (2006). A Consumer-Welfare Approach to Network Neutrality Regulation of the Internet, Journal of Competition Law \& Economics, 2(3), 349-474.

Somogly, R. (2016). The Economics of Zero-Rating and Net Neutrality, CORE Discussion Papers 2016047, Université catholique de Louvain, Center for Operations Research and Econometrics (CORE). https://ideas.repec.org/p/cor/louvco/2016047.html

Rochet, J.C. \& Tirole J. (2003). Platform Competition in Two Sided Markets, Journal of the European Economic Association, 1(4), 990-1029.

Waterman, D., Sherman, R., \& Wook, J.S. (2013). The economics of online television: Industry development, aggregation, and "TV Everywhere", Telecommunications Policy, 37(9), 725-736.

Wu, T. (2003). Network Neutrality, Broadband Discrimination, Journal of Telecommunications and High Technology Law, 2(1), 141-78.

Xing, W., Ye, X., \& Kui, L. (2011). Measuring convergence of Chinas ICT industry: An input output analysis, Telecommunications Policy, 35(4), 301-313.

\footnotetext{
${ }^{\mathrm{i}}$ Pogorel \& Preta (2019) consider AT\&T/Time Warner, 21st Century Fox / Disney, and Comcast/Sky as the three most relevant examples of consolidation.

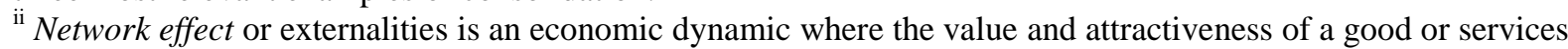
is increased by the numbers of users

${ }^{i i i}$ Cf. Avis n ${ }^{\circ}$ 2016-1551 of the Autorité de régulation des communications électroniques et des postes, 16 November, 2016, to a request of the Competition Authority about the takeover of TPS and Canalsatellite by Vivendi and Canal Plus Group.

${ }^{\text {iv }}$ Free does not invest in content directly, but Xavier Niel, its owner and founder, is present in the press and has launched a $€ 500$ million investment fund called "Media One".

${ }^{\mathrm{v}}$ https://berec.europa.eu/eng/netneutrality/zero_rating/
} 